\title{
Magnetic Behavior and Properties of Electrodeposited Iron Films Undergoing Flash Annealing
}

\author{
Shunichi YOSHIMURA*, Sachio YOSHIHARA*, \\ Takashi SHIRAKASHI* and Eiichi SATO*
}

\section{フラッシュ焼鈍による鉄電析膜の磁気挙動と物性}

\author{
吉村俊一 ${ }^{*}$, 吉原佐知雄 ${ }^{*}$, 白樫高史 ${ }^{*}$, 佐藤栄一*
}

Key Words : Iron Film, Electrodeposition, Magnetic Property, Flash Annealing, Crystal Grain Size

\section{Introduction}

The soft magnetic properties of iron are poor because the coercive force of iron is rather large. Soft magnetic materials, which have lower coercive force and a higher saturated magnetic flux density, were studied by preparing Fe-based alloys and/or compounds ${ }^{11}$. To find new applications for electrodeposited iron film, we studied its crystal structure and properties ${ }^{2), 3)}$. We found that these films showed stronger soft magnetic properties after flash annealing, a method used to improve the soft magnetic properties of Fe-based amorphous alloys. P. Gorria ${ }^{4)}$ and T. Jagielinski et al ${ }^{5)}{ }^{6}{ }^{6}$, have shown that the soft magnetic properties of nanocrystalline alloys obtained from $\mathrm{Fe}$-rich and /or Co-rich amorphous metallic glass could also be improved by flash annealing. Flash annealing is bandy because it can be performed in air, without appreciable oxidation of the sample, thanks to the short heating time, which ranges from some milliseconds to a few seconds.

This paper explores the effects of flash annealing on the magnetic behavior and properties of electrodeposited iron films.

\section{Experiment}

The solution (solution volume; $100 \mathrm{dm}^{3}$ ) for electrodeposition contained $1.57 \mathrm{~mol} / \mathrm{dm}^{3} \mathrm{FeCl}_{2}$ and $2.04 \mathrm{~mol} / \mathrm{dm}^{3} \mathrm{CaCl}_{2}$, and the $\mathrm{pH}$ was adjusted using $\mathrm{HCl}$ solution. The substrate used for deposition was a $99.9 \%$ copper wire $0.080 \mathrm{~mm}$ in diameter which had been annealed beforehand in a furnace, electrodegreased in $\mathrm{NaOH}$ solution,

\footnotetext{
* Fac. of Eng., Utsunomiya Univ. (2753, Ishii-Machi, Utsunomiya-shi, Tochigi 321, Japan)

宇都宮大学 工学部
}

and etched in $\mathrm{HCl}$ solution. The anode was a high-purity iron. Electrolysis was performed under an applied current density of $10 \mathrm{~A} / \mathrm{dm}^{2}$, a solution temperature of $60^{\circ} \mathrm{C}$, and $\mathrm{pH} 2$. The thickness of the deposited iron was $0.8 \mu \mathrm{m}$. Flash annealing and conventional annealing of iron films were performed using an electric furnace $2 \mathrm{~m}$ long in flowing nitrogen gas. The flash annealing time was determined by the speed of the $\mathrm{Fe}$-plated $\mathrm{Cu}$ wire passing through the furnace. The annealing temperature in this study was calculated from heat conduction theory ${ }^{7}$, which implies the actual applied temperature. Magnetic properties were measured using a vibrating-sample magnetometer (Tamagawa : TM-VSM 1550HGC). The crystal grain size $D$ was calculated by Sherrer's expression by measuring the half-life width of the diffraction peak of the (110) plane which was obtained by $\mathrm{X}$-ray diffraction (Rigaku, $\mathrm{Cu}-\mathrm{K} \alpha, \theta: 86-40^{\circ}$ ). The residual stress $\sigma$ of the deposits was measured by X-ray stress measurement (Rigaku : PSPC-MSF-2).

\section{Results and Discussion}

Fig. 1 shows B-H loops of iron films used in as-deposited and flash annealing, the coercive force $(H c)$ for as-deposited was approximately 30 Oe. $\mathrm{Hc}$ for flash annealing at $700^{\circ} \mathrm{C}$ and 2 seconds decreased markedly and the magnetic flux density saturated at a lower magnetic field.

Fig. 2 compares flash annealing and conventional annealing and the effects of annealing temperature on the coercive force, crystal grain size and residual stress in iron films. In conventional annealing, the decreasing temperature of $H c$ agreed with the decreasing temperature of $\sigma$ and the increasing temperature of $D$. $D$ increased markedly above $600{ }^{\circ} \mathrm{C}$, and was $1200 \AA$ at 


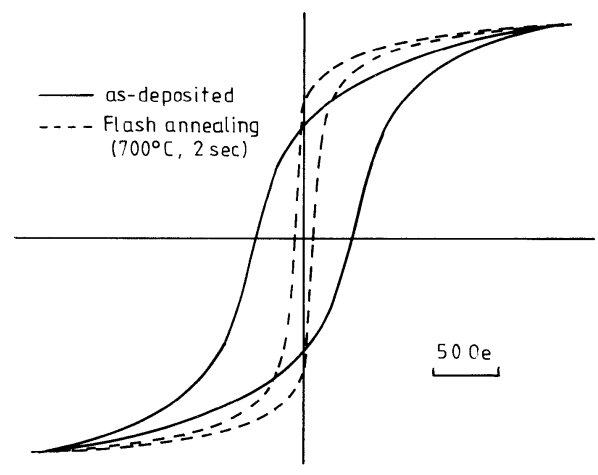

Fig. 1 B-H loops of iron films used in as-deposited and flash annealing $\left(700^{\circ} \mathrm{C}, 2 \mathrm{~s}\right)$.

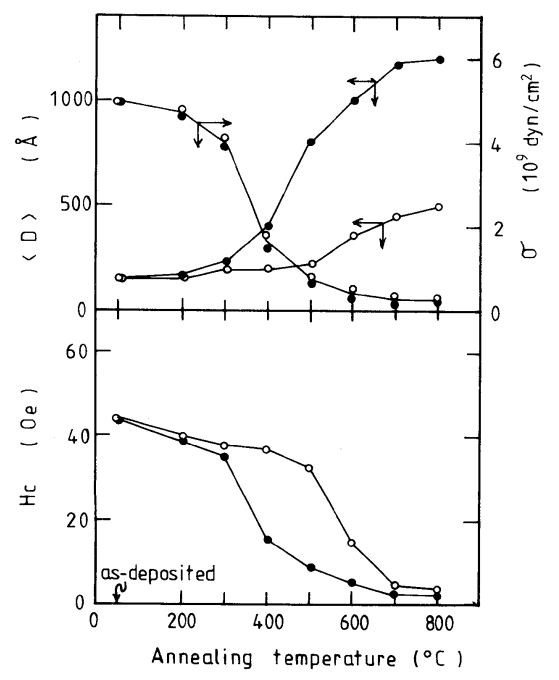

Fig. 2 Comparison of flash annealing $(O: 2 \mathrm{~s})$ and conventional annealing ( $: 2 \mathrm{~h})$ and the effects of annealing temperature on the coercive force $(H c)$, crystal grain size $(D)$, and residual stress $(\sigma)$ in iron films.

$800^{\circ} \mathrm{C}$. In flash annealing, the decreasing temperature of $\mathrm{Hc}$ contrasted with the decreasing temperature of $\sigma$. D was markedly small compared to that in conventional annealing. Thus, flash annealing can be used to obtain iron films with a low $\mathrm{Hc}$ and without a marked increase in $D$.

Fig. 3 compares flash annealing and conventional annealing and the effects of annealing time on the above properties at an annealing temperature of $500^{\circ} \mathrm{C}$. In conventional annealing, some properties of iron films hardly varied and included a low $H c$, a low $\sigma$, and a large $D$. In flash annealing, $H c$ decreased with the in-

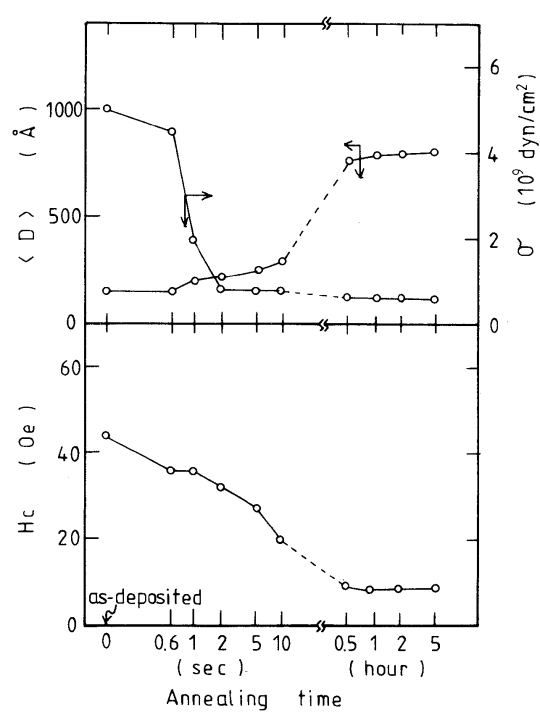

Fig. 3 Comparison of flash annealing and conventional annealing and the effects of annealing time on coercive force $(H c)$, crystal grain size $(D)$, and residual stress $(\sigma)$ in iron films at an annealing temperature of $500^{\circ} \mathrm{C}$.

crease of annealing time. $\sigma$ decreased markedly above 1 second, while $D$ hardly varied.

As indicated above, flash annealing provides certain advantages over conventional annealing. It was of particular interest to find that flash annealing could be used to produce iron films with a low $H c$ and without a marked increase in crystal grain size. This phenomenon is not found in the case of conventional annealing. We surmise that the separation of the behavior of residual stress and crystal grain size in flash annealing leads to the mechanism of the soft magnetization of iron films.

(Received August 31, 1994 ; Accepted October 20, 1994)

\section{References}

1) K. Murakami ; Iron and Steel Inst. Jpn., 73, 1485 (1987)

2) S. Yoshimura, S. Yoshihara, T. Shirakashi, and E. Sato ; Electrochim. Acta, 39, 589 (1994)

3 ) S. Yoshimura, S. Yoshihara, T. Shirakashi, E. Sato, and K. Ishii ; J. Magn. Soc. Jpn., 18, 281 (1994)

4 ) P. Gorria, I. Orue, F. Plazaola, and J. M. Barandiaran ; J. Appl. Phys., 73, 6600 (1993)

5) T. Jagielinski ; IEEE Trans. Magn., MAG-19, 1925 (1983)

6) J. M. Barandiaran, A. Hernando, and O. V. Nielsen ; IEEE Trans. Magn., MAG-22, 1864 (1986)

7 ) S. Awano and T. Kuzuoka ; Dennetsu Kogaku, 2nd ed. (Maruzen, Tokyo, 1961) 